\title{
Diagnostic value of stool DNA testing for multiple markers of colorectal cancer and advanced adenoma: A meta-analysis
}

\author{
Hua Yang $M D^{1,2 *}$, Bing-Qing Xia $M D^{1,2 *}$, Bo Jiang $M D^{1,2}$, Guozhen Wang $M D^{1,2}$, Yi-Peng Yang $M D^{1,2}$, \\ Hao Chen MD,2, Bing-Sheng Li MD³, An-Gao Xu MD', Yun-Bo Huang MD ${ }^{1,2}$, Xin-Ying Wang MD ${ }^{1,2}$
}

H Yang, B-Q Xia, B Jiang, et al. Diagnostic value of stool DNA testing for multiple markers of colorectal cancer and advanced adenoma: A meta-analysis. Can J Gastroenterol 2013;27(8): $467-475$.

BACKGROUND AND OBJECTIVES: The diagnostic value of stool DNA (sDNA) testing for colorectal neoplasms remains controversial. To compensate for the lack of large-scale unbiased population studies, a meta-analysis was performed to evaluate the diagnostic value of sDNA testing for multiple markers of colorectal cancer (CRC) and advanced adenoma.

METHODS: The PubMed, Science Direct, Biosis Review, Cochrane Library and Embase databases were systematically searched in January 2012 without time restriction. Meta-analysis was performed using a random-effects model using sensitivity, specificity, diagnostic OR (DOR), summary ROC curves, area under the curve (AUC), and 95\% Cls as effect measures. Heterogeneity was measured using the $\chi^{2}$ test and Q statistic; subgroup analysis was also conducted.

RESULTS: A total of 20 studies comprising 5876 individuals were eligible. There was no heterogeneity for CRC, but adenoma and advanced adenoma harboured considerable heterogeneity influenced by risk classification and various detection markers. Stratification analysis according to risk classification showed that multiple markers had a high DOR for the high-risk subgroups of both CRC (sensitivity 0.759 [95\% CI 0.711 to 0.804 ]; specificity 0.883 [95\% CI 0.846 to 0.913]; AUC 0.906) and advanced adenoma (sensitivity 0.683 [95\% CI 0.584 to 0.771 ]; specificity 0.918 [95\% CI 0.866 to 0.954]; AUC 0.946 ) but not for the average-risk subgroups of either. In the methylation subgroup, sDNA testing had significantly higher DOR for CRC (sensitivity 0.753 [95\% CI 0.685 to 0.812 ]; specificity 0.913 [95\% CI 0.860 to 0.950]; AUC 0.918) and advanced adenoma (sensitivity 0.623 [ $95 \%$ CI 0.527 to 0.712]; specificity 0.926 [95\% CI 0.882 to 0.958]; AUC 0.910) compared with the mutation subgroup. There was no significant heterogeneity among studies for subgroup analysis.

CONCLUSION: sDNA testing for multiple markers had strong diagnostic significance for CRC and advanced adenoma in high-risk subjects. Methylation makers had more diagnostic value than mutation markers.

Key Words: Adenoma; Colorectal cancer; Diagnosis; Meta-analysis; Stool DNA test

olorectal cancer (CRC) is the third leading cause of cancer death worldwide. Small but steady decreases in CRC mortality have been achieved, in part, by early detection through population-based screening programs (1). Further expansion of screening programs based on the traditional diagnostic methods of CRC and adenoma has been hindered by technique-related limitations, including the

\section{La valeur diagnostique du test d'ADN fécal pour déceler des marqueurs multiples de cancer colorectal et d'adénome avancé : une méta-analyse}

HISTORIQUE ET OBJECTIFS : La valeur diagnostique du test d'ADN fécal (ADNf) pour dépister les néoplasmes colorectaux demeure controversée. Pour compenser l'absence d'études en population à vaste échelle non biaisées, les chercheurs ont mené une méta-analyse afin d'évaluer la valeur diagnostique du test d'ADNf pour déceler des marqueurs multiples du cancer colorectal (CCR) et de l'adénome avancé. MÉTHODOLOGIE : Les chercheurs ont fouillé les bases de données PubMed, Science Direct, Biosis Review, Bibliothèque Cochrane et Embase de manière systématique en janvier 2012, sans restriction dans le temps. Ils ont effectué une méta-analyse au moyen d'un modèle à effets aléatoires dont les mesures d'effet étaient la sensibilité, la spécificité, le RRR diagnostique (RRRD), les courbes ROC sommaires, l'aire sous la courbe (ASC), et les $95 \%$ IC. Ils ont mesuré l'hétérogénéité au moyen du test $\chi^{2}$ et de la statistique $Q$, et ont effectué une analyse de sous-groupe.

RÉSULTATS : Au total, 20 études menées auprès de 5876 personnes étaient admissibles. Il n'y avait pas d'hétérogénéité en cas de CCR, mais l'adénome et l'adénome avancé recelaient une importante hétérogénéité influencée par la classification du risque et divers marqueurs de détection. L'analyse de stratification d'après la classification du risque a révélé que de multiples marqueurs présentaient un RRRD élevé dans les sous-groupes à haut risque de CCR (sensibilité de 0,759 [95 \% IC 0,711 à 0,804$]$, spécificité de 0,883 [95 \% IC de 0,846 à 0,913],ASC de 0,906) et d'adénome avancé (sensibilité de 0,683 [95\% ICI de 0,584 à 0,771], spécificité de 0,918 [95\% IC de 0,866 à 0,954], ASC de 0,946), mais pas dans les sous-groupes à risque moyen de l'un ou de l'autre. Dans le sous-groupe de méthylation, le test d'ADNf présentait un RRRD considérablement plus élevé de CCR (sensibilité de 0,753 [95\% IC de 0,685 à 0,812], spécificité de 0,913 [95\% IC de 0,860 à 0,950], ASC de 0,918 ) et d'adénome avancé (sensibilité de 0,623 [95\% IC de 0,527 à 0,712], spécificité de 0,926 [95\% IC de 0,882 à 0,958], ASC de 0,910) que le sous-groupe de mutation. Il n'y avait pas d'hétérogénéité significative entre les études pour l'analyse de sous-groupe.

CONCLUSION : Le test d'ADNf pour déceler de multiples marqueurs avait une forte signification diagnostique de CCR et d'adénome avancé chez les sujets à haut risque. Les marqueurs de méthylation avaient une plus forte valeur diagnostique que les marqueurs de mutation.

requirement of a visibly detectable lesion, risk of complications, costs and low patient compliance for endoscopy. Thus, the patient-preferred screening method is the fecal occult blood test (FOBT). While the noninvasive nature of this method promotes patient compliance for initial screening, its dependence on the 'bleeding phenotype' and occult bleeding in CRC, regardless of stage, has low sensitivity for accurate

*Authors who contributed equally

${ }^{1}$ Department of Gastroenterology, Nanfang Hospital, Southern Medical University, Guangzhou; ${ }^{2}$ Guangdong Provincial Key Laboratory of

Gastroenterology; ${ }^{3} \mathrm{Huizhou} \mathrm{First} \mathrm{Hospital;}{ }^{4}$ Huizhou Medical Institute, Huizhou, Guangdong, China

Correspondence: Dr Xin-Ying Wang, Department of Gastroenterology, Nanfang Hospital, Southern Medical University, Guangzhou 510515 , China.

Telephone 82-2062787388,fax 82-2062787385,e-mail sunwingwxy@163.com

Received for publication November 12, 2012. Accepted May 6, 2013 
and early diagnosis. Furthermore, the need for repetitive testing negatively impacts patient compliance (2,3). Because adenomas, including advanced adenomas, are usually of small tumour size and do not manifest the bleeding phenotype, the FOBT method is considered to be inadequate. It is, therefore, necessary to develop an alternative noninvasive approach to CRC and adenoma diagnosis with significantly improved accuracy and effectiveness.

Adenoma and carcinoma cells that contain altered DNA are continuously shed into the large bowel lumen and excreted as components of the feces. Because DNA is stable in stool, it can be easily extracted and then differentiated from the large amounts of bacterial DNA that comprise the feces (4). Stool DNA (sDNA) testing represents a promising molecular approach to CRC diagnosis and screening. This procedure is noninvasive, requires no cathartic preparation or patient sedation, and has been shown to be effective with nonfresh and/or preserved specimens, which enables samples to be mailed and eliminates the need for a patient to visit a health care provider. The CRC diagnosis guideline from the American Cancer Society, the United States Multi-Society Task Force on Colorectal Cancer, and the American College of Radiology (ACS-MSTF-ACR) recommended sDNA testing as an appropriate method for average-risk subjects (2). The 2009 CRC screening guidelines from the American College of Gastroenterology also supported sDNA as an alternative screening approach, but recommended a frequency of once every three years (3).

While clinical screening for CRC using sDNA has achieved laudable rates in the general population, the efficacy of this method remains unclear. Studies to date have lacked statistical power and the broad array of study designs has yielded incongruent results. In 1996, Ratto et al (5) evaluated the utility of codon 12 from K-ras for CRC diagnosis and found that clinical detection of this gene sequence could reach $100 \%$ specificity but had 0\% sensitivity. In 2004, Leung et al (6) evaluated the utility of five CRC markers in combination and determined that this method diagnosed $100 \%$ of 20 patients and yielded no false positives. Because cancer is inherently a heterogeneous disease, it is not surprising that many different point mutations have been identified to be significantly associated with colorectal carcinogenesis. The mere presence of an oncogenic mutation in a cell, however, does not guarantee progression to cancer (7) and no single DNA marker has yielded adequate sensitivity for diagnosis of CRC. As a result, the United States Preventive Services Task Force concluded that evidence was insufficient to recommend sDNA as a screening approach.

Previous studies have determined that combinations of markers can produce high detection rates of both CRC and advanced adenomas (8); however, none of the large-scale unbiased population studies that have evaluated the various stages of neoplasm and practical environments have produced a definitive conclusion. Thus, more comprehensive and widescale data are still needed to determine the appropriate panel of markers for sDNA testing. In the present study, we aimed to evaluate the diagnostic value sDNA testing of multiple markers for advanced adenoma and CRC by conducting a formal meta-analysis.

\section{METHODS}

Search strategy and selection criteria

The following databases were systematically searched in January 2012 without time restriction: PubMed, Science Direct, Biosis Review, Cochrane Library and Embase. Key words used in the search strategy included the following: ("faeces" OR "faecal" OR "fecal" OR "stool") AND ("tumour suppressor gene on chromosome 17p" OR "chromosome 17p" OR "tumour suppressor gene" OR "adenomatous polyposis coli" OR "APC" OR "chromosomal instability" OR "deleted in colon cancer" OR "DCC" OR "tumor protein p53" OR "TP53" OR "p53" OR "KRAS" OR "K-ras" OR "BAT-26" OR "microsatellite instability" OR "MSI" OR "mutation" OR "methylation" OR "long DNA" OR "L-DNA"). In addition, the reference lists of all identified studies were manually searched to identify any additional studies. Studies were chosen that investigated the association between sDNA with patients' diagnosis by histopathology (endoscopy) and provided data on the numbers of true positives, false positives, true negatives and false negatives. Articles were excluded if fewer than 10 patients were analyzed; data were insufficient to calculate the $\mathrm{OR}$ as a comparable effect estimate for the numbers of true positives, false positives, true negatives or false negatives; subjects were enrolled without a diagnosis or had undergone recent colonoscopy or sigmoidoscopy; no control group was featured; the study was based on tissue or animals; the study's purpose was to evaluate technical or mechanical aspects of the CRC detection assay; review article or letter; single case report; or conference summary or memorandum. Only English language studies were included. Finally, patient cohorts from each identified study that was not hitherto excluded were carefully examined to identify any potential overlap of patient cohorts with other included studies; all author names, institutions involved and time period of patient recruitment for each publication were compared. In 23 cases, the information was incomplete or unclear, and the corresponding authors for each publication were contacted but very few replied.

Study quality was assessed using the quality assessment tool for studies of diagnostic accuracy (QUADAS [9]), in which a score of +1 was given if a criterion was fulfilled, 0 if it was unclear and -1 if it was not achieved.

\section{Data extraction procedure}

Two reviewers (HY and B-QX) independently extracted the following data from each study: first author, year of publication, study population characteristics (number of patients included, age, sex, tumour stage, gold standard), study design, method(s) of sDNA detection, target gene(s), sampling time (preoperative or postoperative), and number of subjects found to be positive or negative using sDNA testing. The Youden's index was used as the summary measure for the ROC curve and determined for the data from each study assessed. The enrolled subjects were divided into three groups (average risk, high risk and combined) so that risk stratification $(10,11)$ could be accomplished by extracting the risk factors for colorectal disease. The high-risk group included individuals who had symptoms of colorectal disease; family or personal history of CRC or adenomatous polyps, personal history of inflammatory bowel disease and familial polyposis syndromes (including familial adenomatous polyposis and hereditary nonpolyposis colon cancer); voluntarily sought medical assistance for various reasons, or any other specific announcement by the authors. The average-risk group included individuals who were identified by the authors as average risk or those without any of the symptoms or signs listed above. Other subjects with insufficient data or contained both types of subjects were classified as combined-risk individuals. Disagreements were resolved by discussion.

\section{Statistical methods}

Primary outcome measures of the present study were sensitivity, specificity, diagnostic OR (DOR) and summary ROC curve (sROC) of DNA markers in three groups (patients with CRC, patients with adenoma and healthy controls). If the data for true positives, false positives, true negatives and false negatives were not directly provided in the original articles, these values were calculated using a generic spreadsheet (Excel, Microsoft Corporation, USA) and applying the statistical data provided in the article (for example, total patient data or specificity and sensitivity).

A $\mathrm{P}$ value was calculated for pooled estimates and, when $\mathrm{P}<0.05$, a random-effects model was chosen. sROC analysis was performed to assess the interaction between sensitivity and specificity (12). DOR, $Q$ statistic and area under the sROC curve (AUC) were used to analyze the diagnostic value of DNA markers compared with the control group. DOR was calculated from data for sensitivity and specificity analysis, in which a higher DOR indicated a greater diagnostic value. The AUC was used as a measure of the diagnostic value of DNA markers, in which a value of 0.5 indicated a test that was equally likely to diagnose a positive result as either positive or negative. Therefore, a 
TABLE 1

Baseline characteristics of included studies

\begin{tabular}{|c|c|c|c|c|c|c|}
\hline \multirow[b]{2}{*}{ Author (reference), year } & \multicolumn{4}{|c|}{ Patients, n } & \multirow[b]{2}{*}{ Female sex, n (\%) } & \multirow[b]{2}{*}{$\begin{array}{l}\text { Age, years (range) } \\
\text { or mean } \pm S D\end{array}$} \\
\hline & Control & CRC & $\begin{array}{c}\text { Tumour stage } \\
\text { (Dukes) }\end{array}$ & $\begin{array}{c}\text { Adenoma } \\
\text { (advanced) }\end{array}$ & & \\
\hline \multirow[t]{2}{*}{ Ahlquist et al (15), 2000} & 28 & 22 & $A-D$ & $11(11)$ & $31(50.82)$ & Median control 68 (50-77) \\
\hline & & & & & & Adenoma 73 (61-76) \\
\hline Koshiji (16), 2002 & 15 & 30 & NR & NR & NR & NR \\
\hline Calistri et al (17), 2003 & 38 & 53 & A-D & NR & NR & Median control 62 (42-87) \\
\hline Tagore et al (18), 2003 & 212 & 52 & & $28(28)$ & NR & NR \\
\hline Imperiale et al (19), 2004 & 1423 & 31 & & $1051(403)$ & $1392(55.47)$ & Mean 69.5 (NR) \\
\hline Leung et al (6), 2004 & 20 & 20 & B-D & NR & NR & Median 69 (45-90) \\
\hline Kutzner et al (20), 2005 & 44 & 57 & NR & NR & NR & NR \\
\hline \multirow[t]{2}{*}{ Lenhard et al (21), 2005} & 32 & 26 & NR & $13(13)$ & NR & Mean,control 58.8 (23-80) \\
\hline & & & & & & CRC 65.8 (53-80) \\
\hline \multirow[t]{3}{*}{ Jin et al (23) } & 36 & NR & NR & $25(20)$ & NR & Mean control $49.6(\mathrm{NR})$ \\
\hline & & & & & & Adenoma 56.5 (NR) \\
\hline & & & & & & $14(<60$ y) $11(\geq 60$ y) \\
\hline \multirow[t]{2}{*}{ Huang et al (24), 2007} & 24 & 52 & NR & $21(10)$ & NR & Mean control 59.6 (35-68) \\
\hline & & & & & & CRC 63.5 (25-81) \\
\hline \multirow[t]{2}{*}{ Itzkowitz et (25), 2007} & 122 & 40 & NR & NR & NR & Mean control $58.5 \pm 7.2$ \\
\hline & & & & & & CRC $65.6 \pm 10.3$ \\
\hline \multirow[t]{2}{*}{ Wai (26), 2007} & 30 & 20 & NR & $25(8)$ & NR & Mean, CRC 68.8 (45-90) \\
\hline & & & & & & Adenoma 69.9 (46-91) \\
\hline \multirow[t]{2}{*}{ Ahlquist et al (8), 2008} & 75 & 19 & NR & $123(123)$ & $108(49.8)$ & Median 66.4 (7.17) \\
\hline & & & & & & Mean 67 (51-80) \\
\hline \multirow[t]{3}{*}{ Chang et al (31), 2010} & 31 & 30 & NR & $25(8)$ & $37(43.02)$ & Mean control 58.8 \pm 10.2 \\
\hline & & & & & & CRC $61.7 \pm 7.5$ \\
\hline & & & & & & Adenoma $60.1 \pm 8.7$ \\
\hline Zhang et al (32), 2011 & 30 & 60 & NR & $20(9)$ & NR & NR \\
\hline
\end{tabular}

NOTE: Advanced adenoma defined as $\geq 1 \mathrm{~cm}$, or containing high-grade dysplasia or abundant villous elements. CRC Colorectal cancer; NR Not reported; $y$ Years

test that gave the correct diagnosis in $100 \%$ of cases would have an AUC of 1.0. In general practice, most tests achieve a value of between 0.5 and 1.0, with better diagnostic precision correlating with an AUC closer to 1.0. The data from each study having the highest Youden's index were extracted for overall analysis. Statistical analysis was performed using the statistical software packages Stata version 11.1 (StataCorp, USA), meta-disc 1.4 and Review Manager version 5.1.0.

Assessment of risk of bias and sensitivity analyses

Risk of bias was assessed for individual studies by using the risk of bias table, as recommended by the Cochrane Collaboration (13). Sensitivity analysis was performed to assess the impact of high-quality studies (QUADAS score $>8$ ) on sensitivity, specificity, DOR and interstudy heterogeneity. Any articles with a QUADAS score $<8$ were excluded based on inadequate methodological quality. Exclusion of these studies had little effect on either heterogeneity or the diagnostic value of detection
Heterogeneity was measured using the $\chi^{2}$ test and the $Q$ statistic (with $\mathrm{P}<0.05$ considered representative of significant statistical heterogeneity). When statistically significant heterogeneity was identified, sensitivity and specificity data were pooled using the DerSimonian Laird method and analyzed using a random effects model with forest plots and summary estimates generated. In addition to these heterogeneity analyses, the inconsistency index $\mathrm{I}^{2}$, which is a measure to quantify the level of heterogeneity, was calculated.

The statistical analyses were performed using meta-disc 1.4 . Spearman's correlation coefficient between the logit of sensitivity and logit of 1 - specificity was assessed to determine the threshold effect, which is one of the primary causes of heterogeneity in test accuracy studies that arises when differences in sensitivities and specificities occur due to different cut-offs or thresholds used in different studies to define a positive (or negative) test result. Because the presence of a threshold effect indicates the possibility that a correlation between sensitivity and specificity may have 


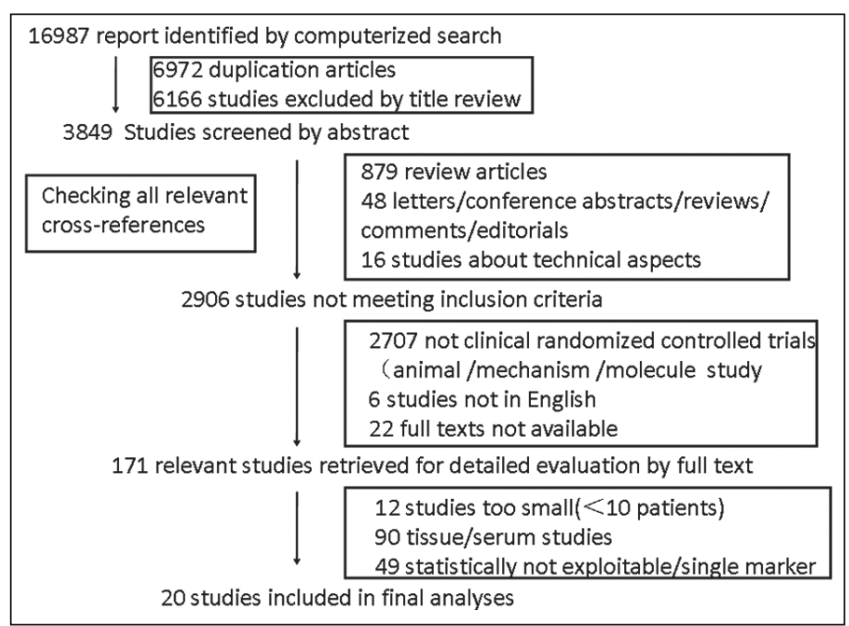

Figure 1) Flow chart of the study selection process for the meta-analysis

arisen due to a number of reasons other than the threshold, in cases when the Spearman's correlation coefficient showed no threshold effect a subgroup analysis was conducted to further explore the sources of heterogeneity (Spearman's correlation coefficients: CRC $0.456 ; \mathrm{P}=0.003$, adenoma $-0.120 ; \mathrm{P}=0.584$ and advanced adenoma $0.022 ; \mathrm{P}=0.932$ ).

Significant heterogeneity was detected in the summary results $(\mathrm{P}<0.0001)$ and was further explored by metaregression and subgroup analyses of perceived covariates. To determine whether the clinical heterogeneity among studies had an effect on the meta-analysis conclusions, subgroup analysis was conducted. Because the effect of diagnosis may vary from one subtype of patients to another, the classification of patients (average risk, high risk and combined risk) was evaluated, as well as study design (different detection markers). In addition, because studies of poorer methodological quality, such as unblinded or open-label trials, may exhibit exaggerated diagnosis effects, comparisons of blinding method and quality index (QUADAS $>8$, and QUADAS $\leq 8$ ) were conducted. The most likely reasons for heterogeneity were explored using metaregression and subgroup analyses to generate DORs. The DOR, calculated using the following formula:

$$
\frac{\text { sensitivity/ } 1-\text { sensitivity }}{1-\text { specificity/specificity }}
$$

is regarded as a measure of the discriminative power of a diagnostic test. In the subgroup analysis, pooled DOR estimates were calculated for various strata to determine whether the test accuracy was higher (as reflected by greater DOR) in specific subgroups. The subgroup analysis identified risk category and marker type as the maximum factors of heterogeneity.

\section{RESULTS}

Baseline study characteristics

The systematic literature search yielded a total of 20 studies for final analysis (Figure 1). Fourteen of these were case-control studies and six were randomized trials. These studies comprised a total of 5876 subjects who underwent sDNA testing and endoscopy. Of these, 817 patients had a diagnosis of CRC, while 1897 had adenoma including 703 with advanced adenoma (14) (defined as $\geq 1 \mathrm{~cm}$, or containing high-grade dysplasia or abundant villous elements). A total of 3162 individuals represented the healthy controls (Table 1). Among the 20 studies (6,8,15-32), data regarding CRC were extracted from 18 and data regarding adenoma from 13 . Twelve studies investigating advanced adenoma were specially abstracted as a subgroup from the adenoma group. The 20 studies had been published between December 1961 and January 12, 2012. All of the studies had analyzed molecular detection methods of DNA from exfoliated cells in the human stool. The study design variables are presented in Table 2. Forest plots were generated to assess sensitivity (true positive rate) and specificity (false positive rate) for the overall data from the 20 studies analyzed (Figure 2).

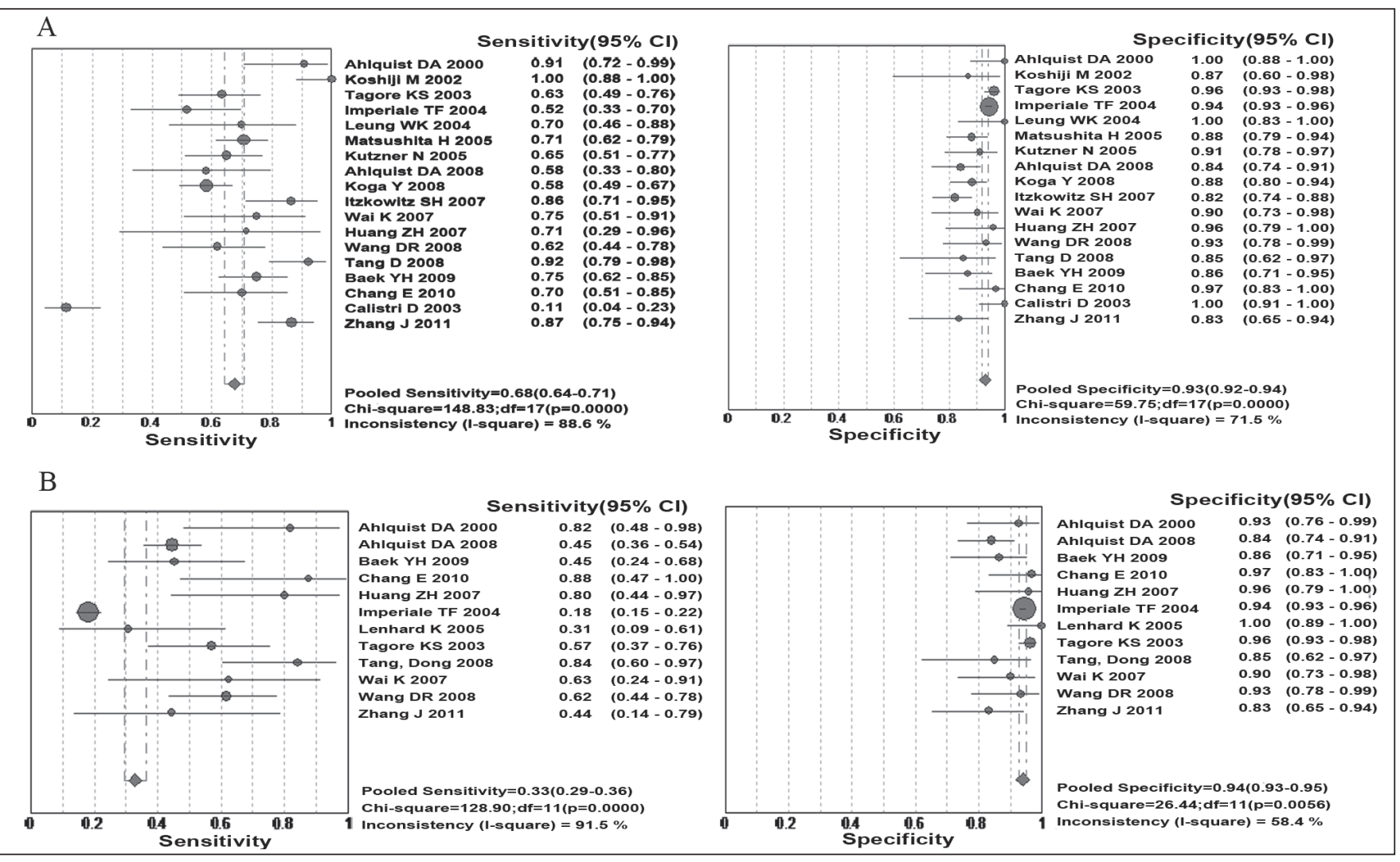

Figure 2) Forest plots of sensitivity and 1-specificity of stool DNA testing in colorectal cancer (A) and advanced adenoma (B). Plots display diagnostic probabilities of included studies with corresponding $95 \%$ CIs with squares indicating area proportional to study weight in the meta-analysis 
TABLE 2

Overview of the study design variables

\begin{tabular}{|c|c|c|c|c|c|c|c|}
\hline \multirow[b]{2}{*}{ Author (reference), year } & \multirow{2}{*}{$\begin{array}{c}\text { Single or multiple } \\
\text { centre }\end{array}$} & \multirow{2}{*}{$\begin{array}{l}\text { Blinding } \\
\text { design }\end{array}$} & \multirow{2}{*}{$\begin{array}{c}\text { Relevant diagnosis } \\
\text { factors }\end{array}$} & \multirow{2}{*}{$\begin{array}{c}\text { Clinical } \\
\text { symptoms }\end{array}$} & \multicolumn{2}{|r|}{ History } & \multirow{2}{*}{$\begin{array}{c}\text { Risk } \\
\text { classification }\end{array}$} \\
\hline & & & & & Personal & Family & \\
\hline Ahlquist et al (14), 2010 & Single & Double & Sex, age, location & Negative & Enrolled & Excluded & High \\
\hline Koshiji et al (16), 2002 & Single & NR & NR & NR & Enrolled & Enrolled & Combined \\
\hline Calistri et al (17), 2003 & NR & NR & NR & NR & Enrolled & NR & Combined \\
\hline Tagore et al (18), 2003 & Multiple & Double & NR & NR & Enrolled & Excluded & Combined \\
\hline Imperiale et al (19), 2004 & Multiple & Triple & NR & Negative & Excluded & Excluded & Average \\
\hline Leung et al (6), 2004 & NR & NR & NR & NR & Enrolled & Excluded & Combined \\
\hline Kutzner et al (20), 2005 & Multiple & NR & Stage & NR & Enrolled & Excluded & Combined \\
\hline Lenhard et al (21), 2005 & Single & Single & NR & Negative & Enrolled & NR & Combined \\
\hline Matsushita et al (22), 2005 & Multiple & Triple & Stage, location & NR & Enrolled & Excluded & High \\
\hline Jin et al (23), 2006 & Single & NR & NR & NR & NR & Excluded & High \\
\hline Huang et al (24), 2007 & Single & Single & NR & NR & NR & NR & High \\
\hline Itzkowitz et al (25), 2007 & Multiple & NR & Stage, location & NR & Enrolled & Excluded & High \\
\hline Wai (26), 2007 & Single & NR & Age & Negative & Excluded & Excluded & Average \\
\hline Ahlquist et al (15), 2000 & Multiple & Triple & Diet and medications & Negative & Excluded & Excluded & Average \\
\hline Koga et al (27), 2008 & Single & NR & Stage, location & NR & Enrolled & NR & Combined \\
\hline Tang et al (28), 2008 & Single & Single & NR & NR & Enrolled & NR & NR \\
\hline Wang and Tang (29), 2008 & Single & Single & NR & NR & NR & Enrolled & High \\
\hline Baek et al (30), 2009 & Single & Triple & NR & Positive & Enrolled & Enrolled & High \\
\hline Chang et al (31), 2010 & Single & Single & NR & Positive & Enrolled & Excluded & High \\
\hline Zhang et al (32), 2011 & Single & Single & Age, sex & Positive & NR & Excluded & Combined \\
\hline \multicolumn{2}{|l|}{ Author (reference), year } & \multicolumn{2}{|c|}{ Sampling time } & \multicolumn{2}{|c|}{ Detection method } & \multicolumn{2}{|l|}{ Target gene } \\
\hline Ahlquist et al (14), 2010 & & \multicolumn{2}{|l|}{ Preoperative } & \multicolumn{2}{|c|}{ Polymerase chain reaction } & \multicolumn{2}{|c|}{ K-ras, p53, APC, Bat-26, L-DNA } \\
\hline Koshiji et al (16), 2002 & & \multicolumn{2}{|l|}{ Preoperative } & \multicolumn{2}{|c|}{ Polymerase chain reaction } & \multicolumn{2}{|c|}{ APC, p53,D9S162 } \\
\hline Calistri et al (17), 2003 & & \multicolumn{2}{|l|}{ Preoperative } & \multicolumn{2}{|l|}{ DGGE/SSCP } & \multicolumn{2}{|c|}{ L-DNA,K-ras,p53, MSI, APC } \\
\hline Tagore et al (18), 2003 & & \multicolumn{2}{|l|}{ Preoperative } & \multicolumn{2}{|c|}{ Polymerase chain reaction } & \multicolumn{2}{|c|}{ K-ras, APC, p53, DIA, BAT-26 } \\
\hline Imperiale et al (19), 2004 & & \multicolumn{2}{|l|}{ Preoperative } & Polymerase ch & eaction & p53, K-ras, APC, & 6 , long DNA \\
\hline Leung et al (6), 2004 & & Preoperative & & Polymerase ch & eaction & ATM, APC, Hmlh & $F, M G M T$ \\
\hline Kutzner et al (20), 2005 & & Preoperative & & Polymerase ch & eaction & $A P C, B A T 26, L-L$ & \\
\hline Lenhard et al (21), 2005 & & Preoperative & & MSP & & HIC1 & \\
\hline Matsushita et al (22), 2005 & & Preoperative & & Polymerase ch & eaction & APC, K-ras, p53, & \\
\hline Jin et al (23), 2006 & & Preoperative & & Polymerase ch & eaction & K-ras, BAT26, BF & \\
\hline Huang et al (24), 2007 & & Preoperative & & MSP & & SFRP2, HPP1, $N$ & \\
\hline Itzkowitz et al (25), 2007 & & Preoperative & & MSP & & $\begin{array}{l}\text { DIA, HLTF, vimer } \\
\text { BAT-26 }\end{array}$ & ras, APC, P53, \\
\hline Wai (26), 2007 & & Preoperative & & MSP & & $\begin{array}{l}\text { APC, ATM, hML } \\
\text { MGMT,GSTP1 }\end{array}$ & RP2, HLTF, \\
\hline Ahlquist et al (15), 2000 & & Preoperative & & Polymerase ch & eaction & $\begin{array}{l}\text { K-ras, APC, p53 } \\
\text { vimentin }\end{array}$ & 26, L-DNA, \\
\hline Koga et al (27), 2008 & & Preoperative & & $\begin{array}{r}\text { Reverse transc } \\
\text { chain reaction }\end{array}$ & on polymerase & $\begin{array}{l}\text { CEA, MMP7, MY } \\
\text { TP53 }\end{array}$ & TTGS2 and \\
\hline Tang et al (28), 2008 & & Preoperative & & MSP & & SFRP1, SFRP2 & \\
\hline Wang and Tang (29), 2008 & & Preoperative - & postoperative & MSP & & SFRP2 & \\
\hline Baek et al (30), 2009 & & Preoperative & & MSP & & MGMT, hMLH1, & \\
\hline Chang et al (31), 2010 & & Preoperative & & MSP & & SFRP2, p16, ITG & \\
\hline Zhang et al (32), 2011 & & Preoperative & & Polymerase ch & eaction (MSP) & TFPI2, L-DNA & \\
\hline
\end{tabular}

Average-risk, patients claimed by author, or patients without any gastrointestinal symptoms and family or personal history of colorectal disease. ${ }^{*}$ High-risk, patients claimed by author or with gastrointestinal symptoms or family or personal history of colorectal disease or those who seek for medical assistance voluntarily. Combined-risk, article contained both kinds of patients or patient information was not available for classification. family or personal history, high-risk conditions for colorectal cancer, such as familial adenomatous polyposis, Lynch syndrome, or other cancer syndromes; previous colorectal cancer or adenoma; inflammatory bowel disease; or more than two first-degree relatives with colorectal neoplasia. DGGE Denaturing gradient gel electrophoresis; MSP Methylation-specific polymerase chain reaction; NR Not reported; SSCP Single-strand conformation polymorphism

Spearman's correlation coefficients of $\mathrm{CRC}(0.456 ; \mathrm{P}=0.003)$, adenoma (-0.120; $\mathrm{P}=0.584)$ and advanced adenoma $(0.022 ; \mathrm{P}=0.932)$ gave no indication of a threshold effect. The sDNA test was determined to be a sensitive method for CRC, without heterogeneity $\left(\mathrm{I}^{2}=27.1 \%\right.$; $\mathrm{P}=0.139)$. However, significant heterogeneity was detected in the data of adenoma $\left(\mathrm{I}^{2}=86.2 \% ; \mathrm{P}<0.0001\right)$ and advanced adenoma $\left(\mathrm{I}^{2}=74.0 \%\right.$;
$\mathrm{P}<0.0001)$. To elucidate the effect of clinical heterogeneity among studies on the meta-analysis' conclusions, subgroup analysis was conducted. Because the effect of diagnosis may vary from one subtype of patients to another, the classification of patients (average risk, high risk and combined risk) was evaluated, as well as the different detection markers (mutation and methylation markers). In addition, because studies of 


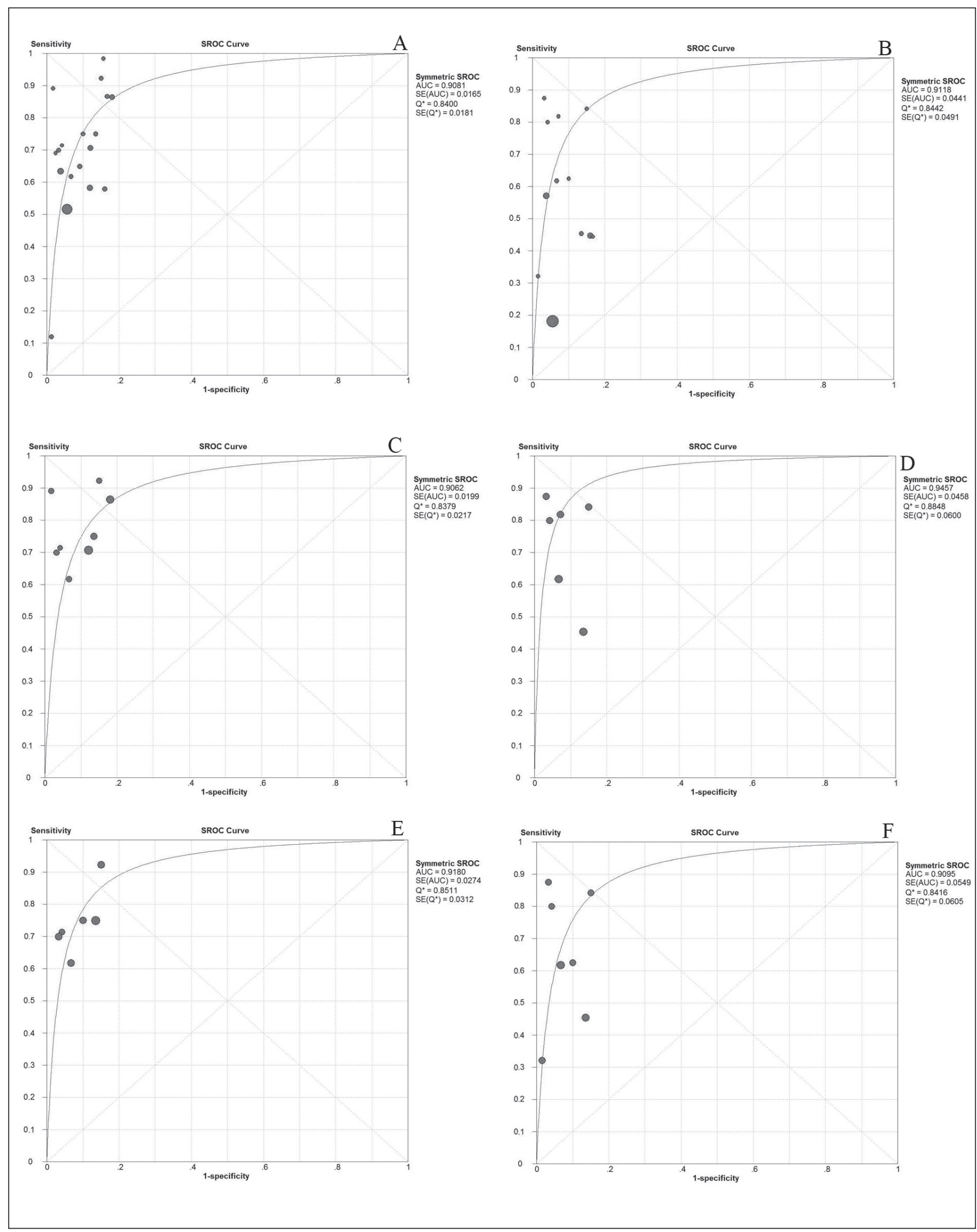

Figure 3) Summary ROC (sROC) plots with $95 \%$ CIs and 95\% predictive ellipses for multiple markers for the detection of colorectal cancer and advanced adenoma in the total population ( $\mathbf{A}$ and $\mathbf{B})$ or in high-risk individuals $(\mathbf{C}$ and $\mathbf{D})$ and according to methylation markers $(\mathbf{E}$ and $\mathbf{F})$. The confidence region consists of the most likely values of true summary sensitivity and specificity, and indicates the precision with which the summary points are estimated. The prediction region predicts the true sensitivity and specificity of a future study, and the size of this region reflects the variation among studies. Individual study estimates are represented by crosses. AUC Area under the curve 
TABLE 3

Stool DNA testing in the detection of colorectal disease

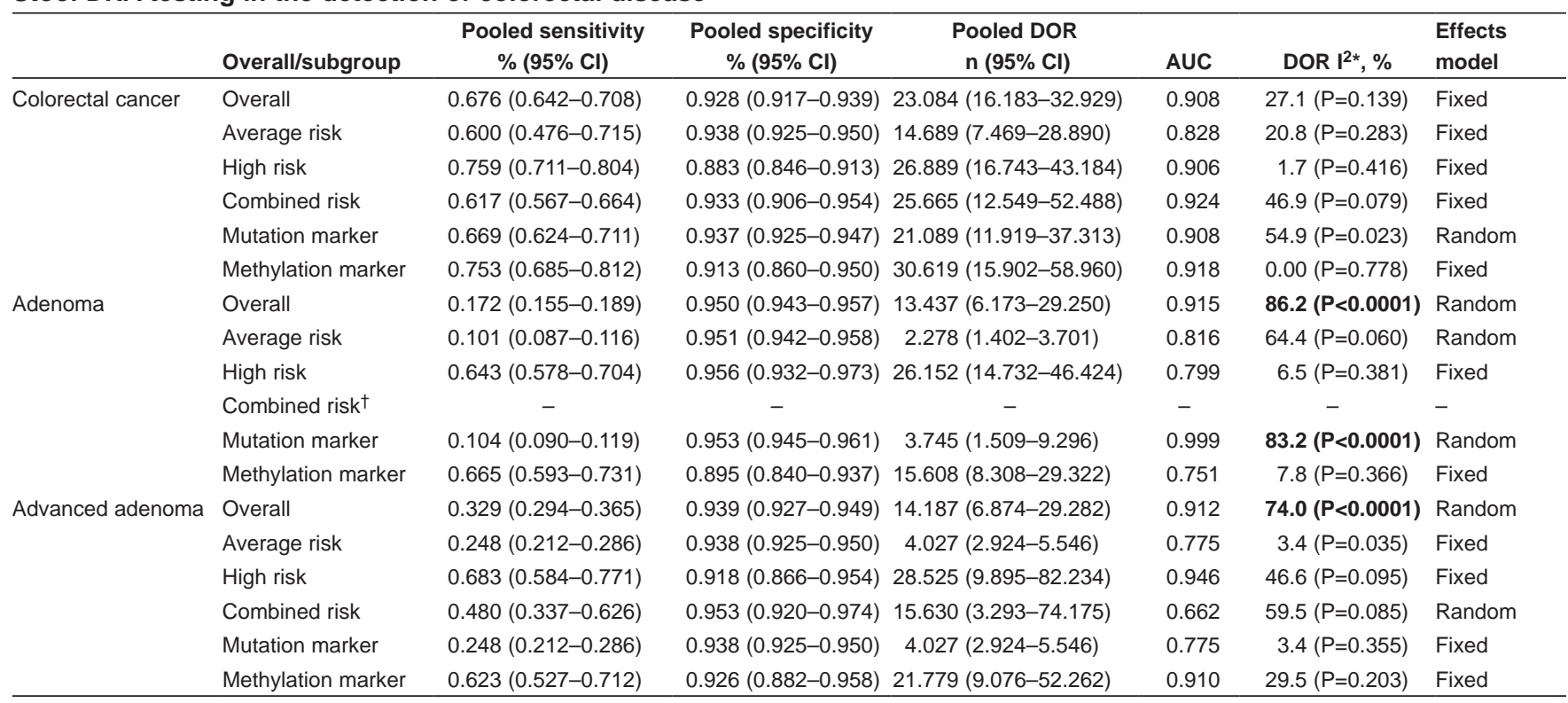

Detection values showing high heterogeneity are shown in bold. *Heterogeneity of diagnostic OR (DOR); ${ }^{+}$Only one study (32) met the classification standard

poorer methodological quality, such as unblinded or open-label trials, may exhibit exaggerated diagnosis effects, a comparison of the blinded method was conducted. Finally, the DOR of sDNA testing showed acceptable heterogeneity for subgroup analysis.

\section{Overall analysis of the diagnostic value of sDNA}

The meta-analysis of CRC detection achieved a sensitivity of 0.676 (95\% CI 0.642 to 0.708 ), specificity of 0.928 (95\% CI 0.917 to 0.939 ) and AUC of 0.908 . The subgroup analyses were repeated for advanced adenoma and achieved sensitivity of 0.329 (95\% CI 0.294 to 0.365$)$, specificity of 0.939 (95\% CI 0.927 to 0.949 ) and AUC of 0.912 (Figure 3).

\section{Subgroup analysis of the risk classifications}

sROC curve analysis of average-risk individuals of CRC produced sensitivity of 0.600 (95\% CI 0.476 to 0.715$)$, specificity of 0.938 (95\% CI 0.925 to 0.950 ) and AUC of 0.828 . The corresponding values for the high-risk individuals were sensitivity of 0.759 (95\% CI 0.711 to 0.804 ), specificity of 0.883 (95\% CI 0.846 to 0.913 ) and AUC of 0.906 . The results of advanced adenoma were similar, with sensitivity of 0.248 ( $95 \%$ CI 0.212 to 0.286 ), specificity of 0.938 (95\% CI 0.925 to 0.950 ) and AUC of 0.775 in average-risk individuals and sensitivity of 0.683 (95\% CI 0.584 to 0.771 ), specificity of 0.918 (95\% CI 0.866 to 0.954 ) and AUC of 0.946 for advanced adenoma in high-risk individuals (Figure 3).

\section{Subgroup analysis of the detection markers}

For methylation markers, a sensitivity of 0.753 (95\% CI 0.685 to 0.812 ), specificity of 0.913 (95\% CI 0.860 to 0.950$)$ and AUC of 0.918 was achieved for CRC detection. The corresponding values for mutation markers were sensitivity of 0.669 (95\% CI 0.624 to 0.711 ), specificity of 0.937 (95\% CI 0.925 to 0.947 ) and AUC of 0.908 . The pooled specificity of methylation markers for advanced adenoma provided sensitivity of 0.623 ( $95 \%$ CI 0.527 to 0.712 ), specificity of 0.926 (95\% CI 0.882 to 0.958 ) and AUC of 0.910 . On the other hand, the corresponding values for the mutation markers were sensitivity of 0.248 (95\% CI 0.212 to 0.286 ), specificity of 0.938 (95\% CI 0.925 to 0.950 ) and AUC of 0.775 . The results for adenoma were similar to those for advanced adenoma (Figure 3). All of the sDNA data are summarized in Table 3.

\section{DISCUSSION}

The mere presence of an oncogene-associated genetic alteration does not guarantee progression to cancer (7). The results of the present meta-analysis highlight the diagnostic value of multiple markers. In contrast, 26 studies that investigated single markers appeared to have low sensitivity but a firm conclusion was precluded by a high level of heterogeneity (data not shown).

In the present analysis, detection of multiple markers via sDNA testing was deemed an accurate and feasible approach for CRC diagnosis (without heterogeneity); however, the analyses of adenoma and advanced adenoma were subject to a considerable level of heterogeneity. Lijmer et al (33) showed that studies with such methodological shortcomings may lead to overestimates of diagnostic accuracy. Therefore, we addressed the heterogeneity with a rigorous methodological approach that used a random-effects model to evaluate the most significant effect of different characteristics such as classification of patients (average risk, high risk or combined risk), detection marker type (mutation or methylation), blinded study design (single, double or triple blinded) and the quality index (QUADAS $>8$ and QUADAS $\geq 8$ ) on the diagnostic accuracy. In the present meta-analysis, DOR was considered to be an aggregative indicator of heterogeneity for both sensitivity and specificity. Risk classification and detection markers were identified as the most significant characteristics influencing diagnostic accuracy. To evaluate the diagnostic value of the sDNA testing method in a more comprehensive aspect, both of the subgroup analyses were conducted for CRC, adenoma and advanced adenoma. Although we lacked sufficient data to analyze all potentially relevant risk factors (such as patients' age, sex and tumour stage), the high detection value of sDNA was consistently found in the pooled analyses of all studies, as well as in all subgroup analyses.

The heterogeneity was significantly decreased when studies were divided according to average risk, high risk and combined risk. These improvements may result from a higher prevalence of genetic and epigenetic alterations and malignant potential in the high-risk subgroup compared with the average-risk subgroup. Therefore, screening programs should be designed with respect to the individuals' level of risk based on personal, family and medical history (10). In 2008, a Joint guideline from ACS-MSTF-ACR concluded that sDNA was an acceptable option for CRC screening in average-risk individuals (2). However, most of the recent guidelines have recommended 
complicated and continual colonoscopies for high-risk individuals without sDNA testing (10). Our data showed that use of multiple marker sDNA testing provided high sensitivity for CRC in high-risk individuals, and sufficient specificity for adenoma and advanced adenoma. Adenomatous polyps represent approximately one-half to twothirds of all colorectal polyps identified in the clinic, and are associated with a higher risk of CRC. The present meta-analysis indicates that sDNA was not suitable for CRC screening in average-risk individuals, yielding a low detection value for precancerous lesions. For high-risk individuals, sDNA not only demonstrated good ability for detecting precancerous lesions but also for promoting patient compliance (compared with endoscopy or FOBT). The patient-related preference for sDNA testing can be further promoted by introducing the general population to screening at an early age and with higher frequency. Indeed, a survey by Berger et al (34) indicated that most individuals are satisfied with the sDNA testing method and would be willing to repeat the test at the recommendation of their physician. The results of the present meta-analysis indicate that sDNA testing is an accurate and feasible alternative to other screening methods for high-risk individuals, but not for average-risk individuals.

Another important factor that can influence the diagnostic value of sDNA testing is the detection marker or panel of markers. In the present meta-analysis, the heterogeneity among studies of different detection markers for cancer progression was assessed by subgroup analysis of methylation and mutation markers. The progression of CRC usually follows a path from benign adenoma to small adenoma to advanced adenoma and, finally, to invasive cancer. Epigenetic alterations, particularly aberrant DNA methylation, are now considered to be the earliest abnormality in this adenoma-to-carcinoma pathogenic sequence (35-39). The present meta-analysis indicated that methylation markers had higher value for early detection, even in the premalignant phase of CRC (advanced adenoma), and significantly higher sensitivity than the mutation markers. Furthermore, methylation markers showed higher sensitivity for CRC detection than mutation markers. This finding may indicate that aberrant methylation of genes along the oncogenic pathway can facilitate progression at later stages of colon carcinogenesis (40). The presented study also suggested that some methylated genes may affect key transformation steps in CRC formation, leading to the rapid accumulation of deleterious genetic alterations. The low specificity may be a result of the tumorigenic multistep process itself, which involves dysregulation of various molecular signalling pathways, each of which may produce asynchronous effects (41). Although the specificity of this combination is too low to merit clinical application, the results suggest that other more sensitive and specific markers and combinations exist.

Our results need to be interpreted in context of the study's strengths and limitations. First, the data from 23 of the studies were unclear. Most of these studies contained very small sample sizes and had low methodological quality, both of which increased the potential bias of data. Second, 26 studies of single markers appeared to have low sensitivity. Our results support the hypothesis that use of multiple markers is superior to the use of single markers, but high heterogeneity precluded our ability to draw a solid conclusion. Furthermore, lack of data inhibited further discussion of the heterogeneity factors related to the single marker studies. To overcome this, subgroup analysis was conducted and helped to uncover some potential sources of heterogeneity. Third, the effect of language selection bias and literature type cannot be ignored; in the present study, we only chose articles that had been published in English. To overcome the potential bias caused by this strategy, any future search strategy should not be limited by publication language and all literature types should be searched. It is important to note, however, that most of the articles found on sDNA testing had been published in English, suggesting that the potential language bias in the current study was minimal. Our selection bias was further minimized by maximizing the sensitivity of the search words, performing the search over a long period of time, and using a variety of databases/search engines, including PubMed, Science Direct, Biosis
Review, Cochrane Library and Embase databases. In addition, the reference lists from articles obtained from the automated searches were verified manually.

\section{SUMMARY}

The present meta-analysis provides coherent evidence that detection of multiple markers via the sDNA method has strong diagnostic significance for CRC and advanced adenoma in high-risk individuals, but not in average-risk individuals. Methylation markers appear to have a stronger diagnostic value than mutation markers, especially for premalignant neoplasms. While these results suggest the clinical value of the sDNA diagnostic method, they also reveal the need for large-scale population-based trials to identify precise methylation markers for early stage detection of CRC and adenoma in a general population that includes both high-risk and average-risk individuals, as well as to determine the optimal sDNA test frequency with respect to cost effectiveness.

AUTHOR CONTRIBUTIONS: Hua Yang and Bing-Qing Xia searched the databases, analyzed the data, and drafted the manuscript. Bo Jiang, Yi-Peng Yang, Hao Chen, Bing-sheng Li, An-Gao Xu and Yun-Bo Huang extracted the data. Xin-Ying Wang conceived and designed the study, analyzed the data and edited the manuscript.

GRANT SUPPORT: This study was supported by grants from the Science and Technology Planning Project of Guangdong Province (No. 2010B031600098) and the Science and Technology Development Program of Guangzhou Municipality (No. 2060402).

FUNDING: The cost of this study was borne by the authors' institutions with the grants listed in the Grant Support statement.

DISCLOSURES: The authors have no financial disclosures or conflicts of interest to declare.

\section{REFERENCES}

1. Edwards BK, Ward E, Kohler BA, et al. Annual report to the nation on the status of cancer, 1975-2006, featuring colorectal cancer trends and impact of interventions (risk factors, screening, and treatment) to reduce future rates. Cancer 2010;116:544-73.

2. Levin B, Lieberman DA, McFarland B, et al. Screening and surveillance for the early detection of colorectal cancer and adenomatous polyps, 2008: A joint guideline from the American Cancer Society, the US Multi-Society Task Force on Colorectal Cancer, and the American College of Radiology.

Gastroenterology 2008;134:1570-95.

3. Rex DK, Johnson DA, Anderson JC, Schoenfeld PS, Burke CA, Inadomi JM. American College of Gastroenterology guidelines for colorectal cancer screening 2009 [corrected]. Am J Gastroenterol 2009;104:739-50.

4. Sidransky D, Tokino T, Hamilton SR, et al. Identification of ras oncogene mutations in the stool of patients with curable colorectal tumors. Science 1992;256:102-5.

5. Ratto C, Flamini G, Sofo L, et al. Detection of oncogene mutation from neoplastic colonic cells exfoliated in feces. Dis Colon Rectum 1996;39:1238-44.

6. Leung WK, To KF, Man EP, et al. Detection of epigenetic changes in fecal DNA as a molecular screening test for colorectal cancer: A feasibility study. Clin Chem 2004;50:2179-82.

7. Grady WM, Carethers JM. Genomic and epigenetic instability in colorectal cancer pathogenesis. Gastroenterology 2008;135:1079-99.

8. Ahlquist DA, Sargent DJ, Loprinzi CL, et al. Stool DNA and occult blood testing for screen detection of colorectal neoplasia. Ann Intern Med 2008;149:441-50:W481.

9. Whiting P, Rutjes AW, Dinnes J, Reitsma J, Bossuyt PM, Kleijnen J. Development and validation of methods for assessing the quality of diagnostic accuracy studies. Health Technol Assess 2004;8:iii, 1-234.

10. Winawer S, Fletcher R, Rex D, et al. Colorectal cancer screening and surveillance: Clinical guidelines and rationale-update based on new evidence. Gastroenterology 2003;124:544-60. 
11. Davila RE, Rajan E, Baron TH, et al. ASGE guideline: Colorectal cancer screening and surveillance. Gastrointest Endosc 2006;63:546-57.

12. Jones CM, Athanasiou T. Summary receiver operating characteristic curve analysis techniques in the evaluation of diagnostic tests. Ann Thorac Surg 2005;79:16-20.

13. Higgins JPT, Green S, Cochrane Collaboration. Cochrane Handbook for Systematic Reviews of Interventions. Chichester: Wiley-Blackwell, Hoboken, NJ, 2008.

14. Ahlquist DA. Molecular detection of colorectal neoplasia. Gastroenterology 2010;138:2127-39.

15. Ahlquist DA, Skoletsky JE, Boynton KA, et al. Colorectal cancer screening by detection of altered human DNA in stool. Feasibility of a multitarget assay panel. Gastroenterology 2000;119:1219-27.

16. Koshiji M. Microsatellite analysis of fecal DNA for colorectal cancer detection. J Surg Oncol 2002;80:34-40.

17. Calistri D, Rengucci C, Bocchini R, Saragoni L, Zoli W, Amadori D. Fecal multiple molecular tests to detect colorectal cancer in stool. Clin Gastroenterol Hepatol 2003;1:377-83.

18. Tagore KS, Lawson MJ, Yucaitis JA, et al. Sensitivity and specificity of a stool DNA multitarget assay panel for the detection of advanced colorectal neoplasia. Clin Colorectal Cancer 2003;3:47-53.

19. Imperiale TF, Ransohoff DF, Itzkowitz SH, Turnbull BA, Ross ME. Fecal DNA versus fecal occult blood for colorectal-cancer screening in an average-risk population. N Engl J Med 2004;351:2704-14.

20. Kutzner N, Hoffmann I, Linke C, et al. Non-invasive detection of colorectal tumours by the combined application of molecular diagnosis and the faecal occult blood test. Cancer Lett 2005;229:33-41.

21. Lenhard K, Bommer GT, Asutay S, et al. Analysis of promoter methylation in stool: A novel method for the detection of colorectal cancer. Clin Gastroenterol Hepatol 2005;3:142-9.

22. Matsushita H, Matsumura Y, Moriya Y, et al. A new method for isolating colonocytes from naturally evacuated feces and its clinical application to colorectal cancer diagnosis. Gastroenterology 2005;129:1918-27.

23. Jin YM, Li BJ, Qu B, Du YJ. BRAF, K-ras and BAT26 mutations in colorectal polyps and stool. World J Gastroenterol 2006;12:5148-52.

24. Huang ZH, Li LH, Yang F, Wang JF. Detection of aberrant methylation in fecal DNA as a molecular screening tool for colorectal cancer and precancerous lesions. World J Gastroenterol 2007;13:950-4.

25. Itzkowitz SH, Jandorf L, Brand R, et al. Improved fecal DNA test for colorectal cancer screening. Clin Gastroenterol Hepatol 2007;5:111-7.

26. Wai K. Detection of hypermethylated DNA or cyclooxygenase-2 messenger RNA in fecal samples of patients with colorectal cancer or polyps. Am J Gastroenterol 2007;102:1070-6.
27. Koga Y, Yasunaga M, Moriya Y, et al. Detection of colorectal cancer cells from feces using quantitative real-time RT-PCR for colorectal cancer diagnosis. Cancer Sci 2008;99:1977-83.

28. Tang D, Wang D, Li H: Combination analysis of hypermethylated SFRP1 and SFRP2 gene in fecal as a novel epigenetic biomarker panel for colorectal cancer screening. J Nanjing Medical University 2008;22:96-101.

29. Wang DR, Tang D. Hypermethylated SFRP2 gene in fecal DNA is a high potential biomarker for colorectal cancer noninvasive screening. World J Gastroenterol 2008;14:524-31.

30. Baek YH, Chang E, Kim YJ, Kim BK, Sohn JH, Park DI. Stool methylation-specific polymerase chain reaction assay for the detection of colorectal neoplasia in Korean patients. Dis Colon Rectum 2009;52:1452-9; discussion 1459-63.

31. Chang E, Park DI, Kim YJ, et al. Detection of colorectal neoplasm using promoter methylation of ITGA4, SFRP2, and p16 in stool samples: A preliminary report in Korean patients. Hepatogastroenterology 2010;57:720-7.

32. Zhang J, Yang S, Xie Y, et al. Detection of methylated tissue factor pathway inhibitor 2 and human long DNA in fecal samples of patients with colorectal cancer in China. Cancer Epidemiol 2012;36:73-7.

33. Lijmer JG, Mol BW, Heisterkamp S, et al. Empirical evidence of design-related bias in studies of diagnostic tests. JAMA 1999;282:1061-6.

34. Berger BM, Schroy PC III, Rosenberg JL, et al. Colorectal cancer screening using stool DNA analysis in clinical practice: Early clinical experience with respect to patient acceptance and colonoscopic follow-up of abnormal tests. Clin Colorectal Cancer 2006;5:338-43.

35. Baylin SB, Herman JG, Graff JR, Vertino PM, Issa JP. Alterations in DNA methylation: A fundamental aspect of neoplasia. Adv Cancer Res 1998;72:141-96.

36. Bird A. The essentials of DNA methylation. Cell 1992;70:5-8.

37. Merlo A, Herman JG, Mao L, et al. 5' CpG island methylation is associated with transcriptional silencing of the tumour suppressor p16/CDKN2/MTS1 in human cancers. Nat Med 1995;1:686-92.

38. Esteller M. Cancer epigenomics: DNA methylomes and histonemodification maps. Nat Rev Genet 2007;8:286-98.

39. Esteller M, Fraga MF, Guo M, et al. DNA methylation patterns in hereditary human cancers mimic sporadic tumorigenesis. Hum Mol Genet 2001;10:3001-7.

40. Kim MS, Lee J, Sidransky D. DNA methylation markers in colorectal cancer. Cancer Metastasis Rev 2010;29:181-206.

41. Foulds L. The natural history of cancer. J Chronic Dis 1958;8:2-37. 


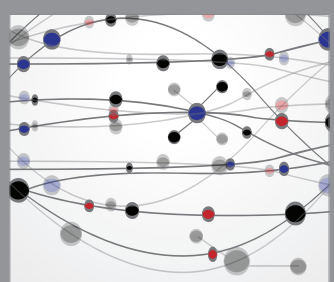

The Scientific World Journal
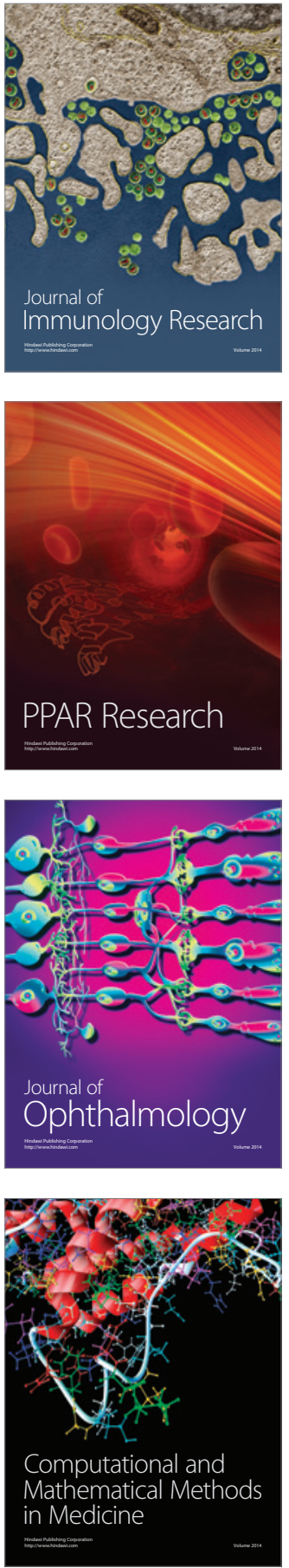

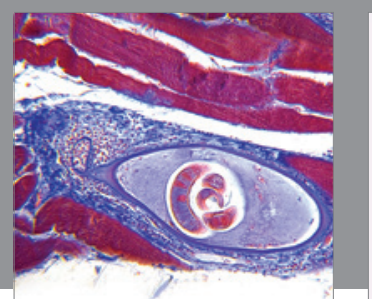

Gastroenterology Research and Practice

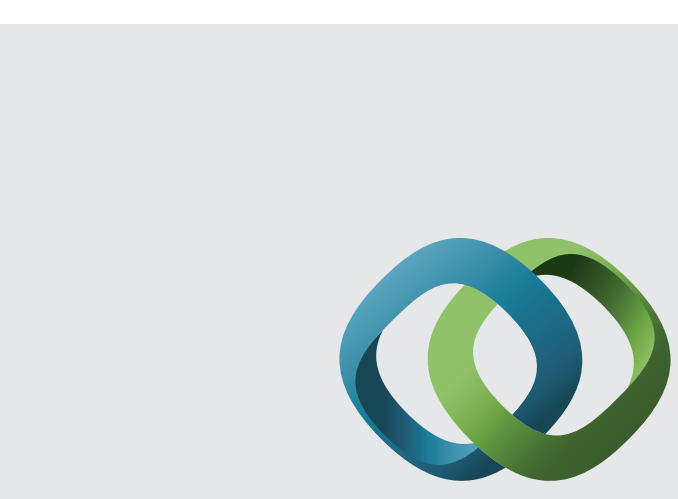

\section{Hindawi}

Submit your manuscripts at

http://www.hindawi.com
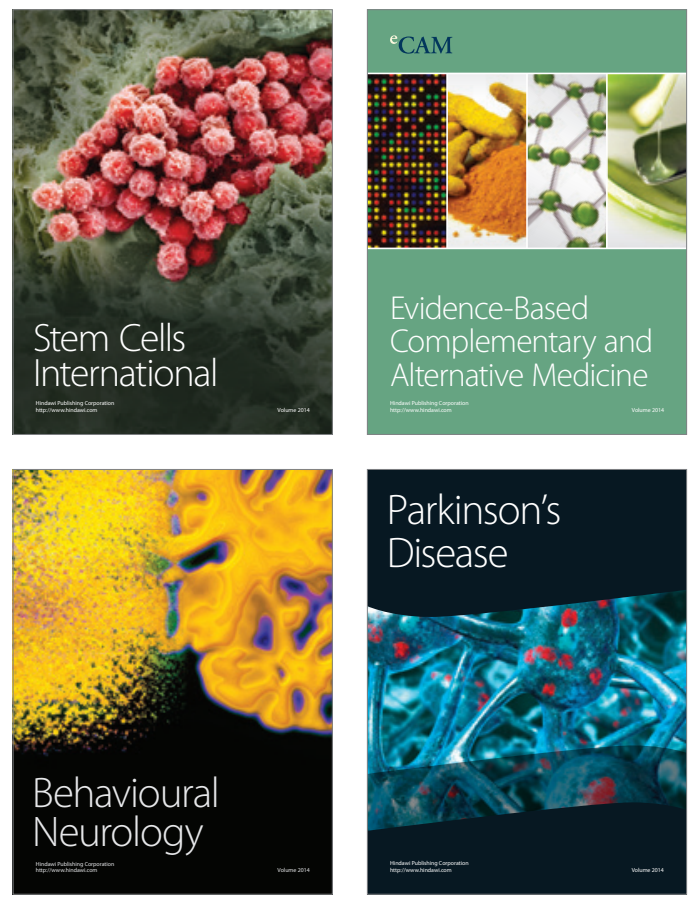
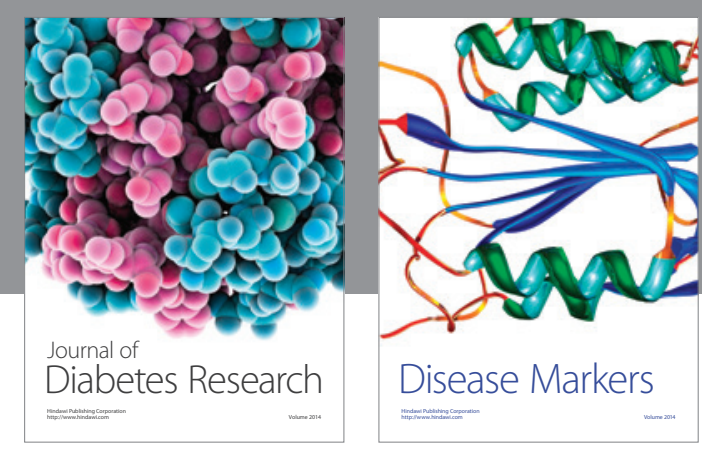

Disease Markers
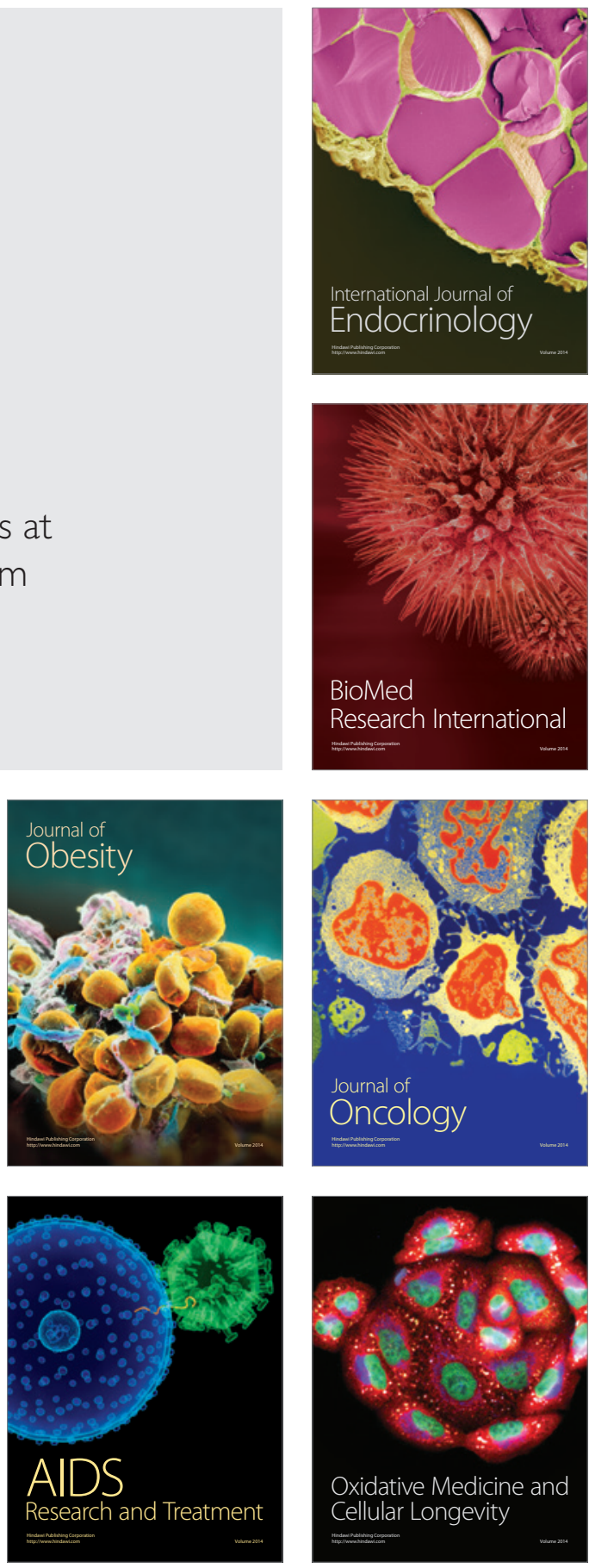